\title{
A IMPORTÂNCIA DA HUMANIZAÇÃO PARA A FORMAÇÃO MÉDICA ATRAVÉS DE UMA ANÁLISE BIBLIOMÉTRICA
}

\author{
Tiago Andrade Muniz TERRA ${ }^{2}$, Luciana de Oliveira Fumian BRASIL ${ }^{1}$, Gilmara Mageste VON HELD ${ }^{1}$, \\ Mariacélia Fernandes ROCHA ${ }^{1}$, Renata Caraline Carvalhal FRAGA ${ }^{1}$, Mychelly Dias de Medeiros CHIARELLI ${ }^{1}$ \\ \& Cristiano Manhães de OLIVEIRA ${ }^{2}$
}

1Universidade Iguaçu - Campus V. Itaperuna, Rio de Janeiro, Brasil.

2Universidade Estadual do Norte Fluminense Darcy Ribeiro. Campos dos Goytacazes, Rio de Janeiro, Brasil.

*Autor para correspondência: tiagoterra@pq.uenf.br

DOI: http://dx.doi.org/10.18571/acbm.170

\section{RESUMO}

A humanização em saúde vem ganhando destaque pela necessidade de estabelecer uma prática assistencial que não contemple apenas as necessidades fisiológicas do ser humano, mas que possa interligar os determinantes biopsicossociais a fim de promover um cuidado integral a sua saúde. Para tal finalidade, é necessário o conhecimento acerca dessa temática. O presente trabalho elucida a importância da humanização em saúde através da análise da produção científica contida na base de dados Scopus, contribuindo para a construção de uma relação médica baseada nas consternações do paciente e nas práticas de educação em saúde, preconizada pelas Diretrizes Curriculares Nacionais do Curso de Medicina. Assim foi possível identificar o crescente interesse dos pesquisadores brasileiros pela temática "humanização em saúde" devido ao grande número de publicações encontradas.

Palavras chave: Educação em Saúde; Humanização; Bibliometria; Análise de Dados.

\begin{abstract}
Humanization in health has been highlighted by the need to establish a care practice that does not only contemplate the physiological needs of the human being, but which can interconnect the biopsychosocial determinants in order to promote integral health care. For this purpose, knowledge about this subject is necessary. This paper elucidates the importance of humanization in health through analysis of the scientific production contained in the Scopus database, contributing to the construction of a medical relation based on patient dismay and health education practices, as recommended by the National Curriculum Guidelines Medicine course. Thus, it was possible to identify the growing interest of Brazilian researchers in the theme "humanization in health" due to the large number of publications found.
\end{abstract}

Keywords: Health Education; Humanization; Bibliometric; Data analysis.

\section{Introdução}

O termo "humanização", em seu sentido histórico, foi consagrado como aquele que retoma valores e princípios éticos enternecidos pelo ser humano. Sabe-se que após a era moderna surgiu o período que muitos chamam de pós-modernidade. Viu-se que a ciência e a razão não conseguiram dar conta dos anseios e questões do homem, razão pela qual as pessoas, descrentes com os ideais utópicos 
propostos na modernidade, deixaram de acreditar nos coletivos sociais e passaram a valorizar, cada vez mais, a si mesmas. Isso ensejou um individualismo profundo, o qual resultou em extrema intolerância com o outro, com o diferente (RIOS, 2009).

Diante disso, surgiu a necessidade de humanização das relações, a fim de que os valores éticos, morais, respeito, dentre outros, fossem erigidos a patamares essenciais, pois a "medicina é uma prática ético-dependente, ou seja, ainda que o mundo se acabe em um livre agredir, em que vença o mais forte, o mais rico, ou o mais bonito, na área da saúde é imprescindível a educação para a ética nas relações entre as pessoas, sem a qual não é possível realizar missão que nos destina essa escolha profissional" (SCHRAIBER, 1997).

Ademais, com a globalização e o avanço da modernidade, as técnicas científicas foram erigidas a um patamar de maior atenção. Os pacientes foram colocados em segundo plano, eis que os médicos e a ciência médica assumiram a posição de destaque nessa relação. Isso fez com que ocorresse a perda da unidade do indivíduo e consequente declínio da relação médico-paciente (TODRES, GALVIN e DAHLBERG, 2007).

Partindo-se de tal premissa, verifica-se que a comunicação é um elemento primordial para o estabelecimento de uma relação humanizada entre o médico e o paciente. Ou seja, "a capacidade de se estabelecer uma adequada comunicação entre as partes é de inquestionável importância, tornandose o alicerce para a construção da confiança e da credibilidade" (LEE, 2004).

Assim, o embasamento científico acerca dessa temática, baseado em estudos e pesquisas relevantes, torna-se imperioso para a construção da formação médica humanizada e que atenda os preceitos de atenção à saúde pautados na tríade biopsicossocial, nas questões subjetivas, o que será de grande vaia para a compreensão dos processos mórbidos e para a busca de soluções.

Com isso, o objetivo do trabalho é identificar as publicações científicas a nível mundial por meio da aplicação bibliométrica na base Scopus para mapear a produtividade científica sobre o tema humanização em saúde, tendo como base o procedimento adotado por Aria e Cuccurullo (2017).

\section{Revisão Bibliográfica}

A Humanização em Saúde vem sendo amplamente difundida nos dias atuais, principalmente pela necessidade de promover relações mais humanas entre o cuidado, a assistência e o usuário do serviço de saúde. Por estar interligada no campo da ética a humanização é fundamental, pois busca acordos de cooperação pautados em valores humanos coletivamente pactuados. Neles há respeito, compaixão, bondade (OLIVEIRA, COLLET e VIERA, 2006).

A interação que valora o ser humano é muita mais ampla e eficaz, sendo capaz de melhor diagnosticar os problemas e buscar as soluções. Além disso, ela é importante para a melhora no ambiente de trabalho, pois visa a participação de todos no processo, o que envolve aspectos multidisciplinares, fator este de extrema contribuição para o constante aprimoramento das relações entre profissionais de saúde e pacientes (LEE, 2004).

No Brasil, as pesquisas sobre a humanização em saúde vêm auferindo um expressivo realce, principalmente no que tange ao grande número de trabalhos realizados nos últimos anos, consagrandose, desde a década de 70, como o país que ocupa o primeiro lugar no ranking em todo o mundo, atingindo o marco de $48 \%$ dessas produções científicas (ELSEVIER B. V., 2017).

Tamanha a significância desta temática que foi criado, no ano de 2003, pelo Ministério da Saúde a Política Nacional de Humanização tendo como princípios básicos a "transversalidade, a indissociabilidade entre a atenção e gestão, e o protagonismo, corresponsabilidade e autonomia dos sujeitos e coletivo". Através desta política foi criado um portal colaborativo para educação e discussão de assuntos relacionados a esse tema, onde participam estudantes, profissionais de saúde, 
pesquisadores, entre outros, todos com objetivo comum de "conhecer melhor, ampliar e colocar na roda de conversa o tema humanização (BRASIL, 2004).

Diante disso, pode-se perceber que humanizar é ir muito além de um ambiente fisicamente preparado e ornamentado, boas roupas e pessoas de boa aparência. É criar vínculo, laços de afetividade, cuidado, amor e respeito ao próximo (TODRES, GALVIN e HOLLOWAY, 2009).

Assim, o presente trabalho evidencia a importância da humanização em saúde através da análise da produção científica contida na base de dados Scopus, contribuindo para a construção de uma relação médica baseada nas consternações do paciente e nas práticas de educação em saúde, preconizada pelas Diretrizes Curriculares Nacionais do Curso de Medicina.

\section{Metodologia}

A presente investigação foi produzida através de Revisões de Mapeamento Sistemático que são usadas para estruturar uma área de pesquisa (PETERSEN, VAKKALANKA e KUZNIARZ, 2015). A partir desta, constatou-se que existe um número cada vez maior de artigos sendo publicado, fazendo com que o rastreamento bibliográfico seja um método cada vez mais importante para o rastreamento de informações relevantes para a pesquisa (KNUTAS et al., 2015).

A extração de dados de produção acadêmica, identificação de padrões bibliométricos, modelagem e visualização das redes de interação entre coautores são tópicos relevantes na área de Bibliometria e Cientometria (MENA-CHALCO e JUNIOR, 2009). A Análise de Redes Sociais (ARS), não é uma teoria formal em sociologia, mas uma estratégia para investigar as estruturas sociais, onde são estudadas as redes de colaboração, além de outras formas de iteração das redes sociais, além disso, a Internet representa uma rede social em uma escala sem precedentes (OTTE e ROUSSEAU, 2002).

Entretanto, hoje em dia, com advento da Internet, correlacionar autores e publicações fidedignas, está ficando cada vez mais difícil, devido ao crescente volume de informações (KLINK et al., 2006). As redes de material acadêmico têm grande quantidade de informações. Aproximadamente 114 milhões de documentos científicos (tais como livros, artigos, teses, dissertações e documentos técnicos), somente em inglês, são hoje acessíveis pela web (KHABSA e GILES, 2014).

Para o desenvolvimento deste trabalho foram adotados métodos similares aos usados por Aria e Cuccurullo (2017), a metodologia é resumida na Figura 1:

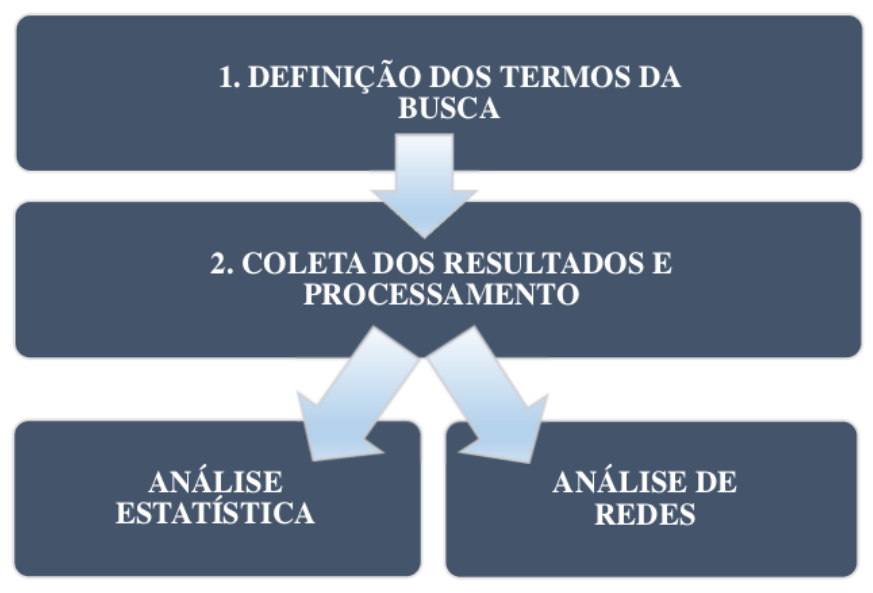

Figura 1: Metodologia utilizada. 
Dessa forma, foi utilizada a base de dados Scopus, por se tratar de uma base de dados mais abrangente, incluindo uma gama maior de periódicos comparado a PubMed e Web of Science (FALAGAS et al., 2007), onde foi realizada a seguinte consulta: "HUMANIZATION" AND "HEALTH*", onde essas palavras poderiam aparecer no título, resumo ou palavras-chave dos artigos. A pesquisa foi realizada em novembro de 2017 abrangendo todo o período temporal da base, retornando 855 documentos.

Para manipulação dos dados foi utilizada a ferramenta $R$ (R Development Core Team, 2010), juntamente aos pacotes wordcloud (FELLOWS, 2014), rworldmap (SOUTH, 2011) e bibliometrix (ARIA e CUCCURULLO, 2017). A seguir são demonstrados os resultados gerados, tais como principais autores, periódicos, países e palavras chave.

\section{Resultados}

Como resultado deste trabalho, obteve-se um resumo dos dados quantitativos da pesquisa, dividindo a análise em duas partes, conforme apontado na metodologia. Primeiramente foi realizada uma análise estatística das publicações, pesquisando a distribuição cronológica dos artigos para em seguida levantar outras informações relevantes ao tema proposto, tais como: autores, artigos, journals (periódicos), palavras, instituições e as áreas em que são publicados. Depois é executada uma análise de redes.

\subsection{Análise Estatística \\ 4.1.1 Distribuição Cronológica}

A figura 02 mostra a distribuição cronológica das publicações, tendo como o primeiro registro no ano de 1970, e apresentando um expressivo processo de expansão a partir do ano de 2000 com um ápice em 2016, chegando ao patamar de 86 publicações somente nesse ano.

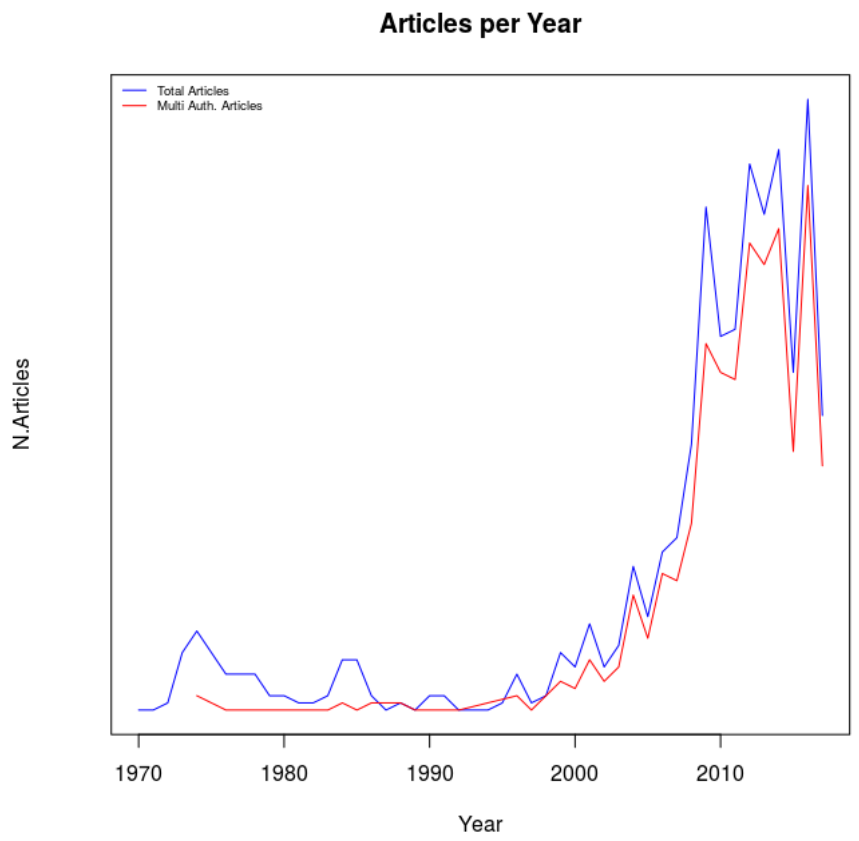

Figura 2: Evolução das publicações ao longo dos anos. 


\subsubsection{Periódicos mais importantes}

$\mathrm{Na}$ tabela 1 são mostrados os periódicos que mais publicam sobre o tema, sendo o "INTERFACE: COMMUNICATION HEALTH EDUCATION" o mais ativo com um total de 72 publicações, seguido do "CIÊNCIA E SAÚDE COLETIVA" com 42 e o terceiro é o periódico "SAÚDE E SOCIEDADE" com 31 publicações.

Tabela 1: Periódicos mais importantes.

\begin{tabular}{lcc}
\hline \multirow{2}{*}{ Periódico } & No de Publicações & CiteScore \\
& & \\
\hline INTERFACE: COMMUNICATION HEALTH EDUCATION & 72 & 0,34 \\
\hline CIENCIA E SAUDE COLETIVA & 42 & 0,85 \\
\hline SAUDE E SOCIEDADE & 31 & 0,39 \\
\hline REVISTA BRASILEIRA DE ENFERMAGEM & 26 & 0,45 \\
\hline CADERNOS DE SAUDE PUBLICA & 21 & 1,05 \\
\hline ONLINE BRAZILIAN JOURNAL OF NURSING & 21 & 0,22 \\
\hline TEXTO E CONTEXTO ENFERMAGEM & 18 & 0,56 \\
\hline REVISTA LATINO-AMERICANA DE ENFERMAGEM & 17 & 1,01 \\
\hline REVISTA DA ESCOLA DE ENFERMAGEM & 16 & 0,48 \\
\hline REVISTA DE SAUDE PUBLICA & 16 & 1,65 \\
\hline
\end{tabular}

\subsubsection{Países mais importantes}

No que diz respeito aos países mais produtivos em relação a temática humanização em saúde a figura 03 demonstra o ranking de nações que apresentam maior número de publicações, estando o Brasil em primeiro lugar.

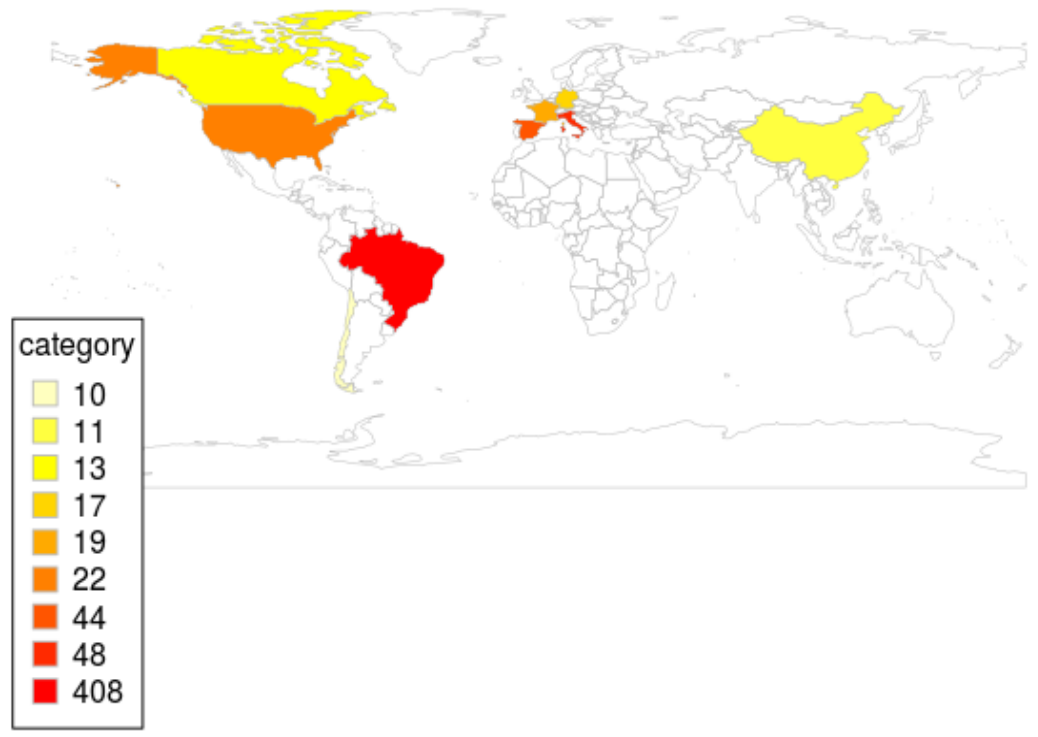

Figura 3: Países com mais publicações. 
Quando se trata do número de citações, o Brasil também se mantém em primeiro lugar. Fato que pode ser evidenciado através da figura 4.

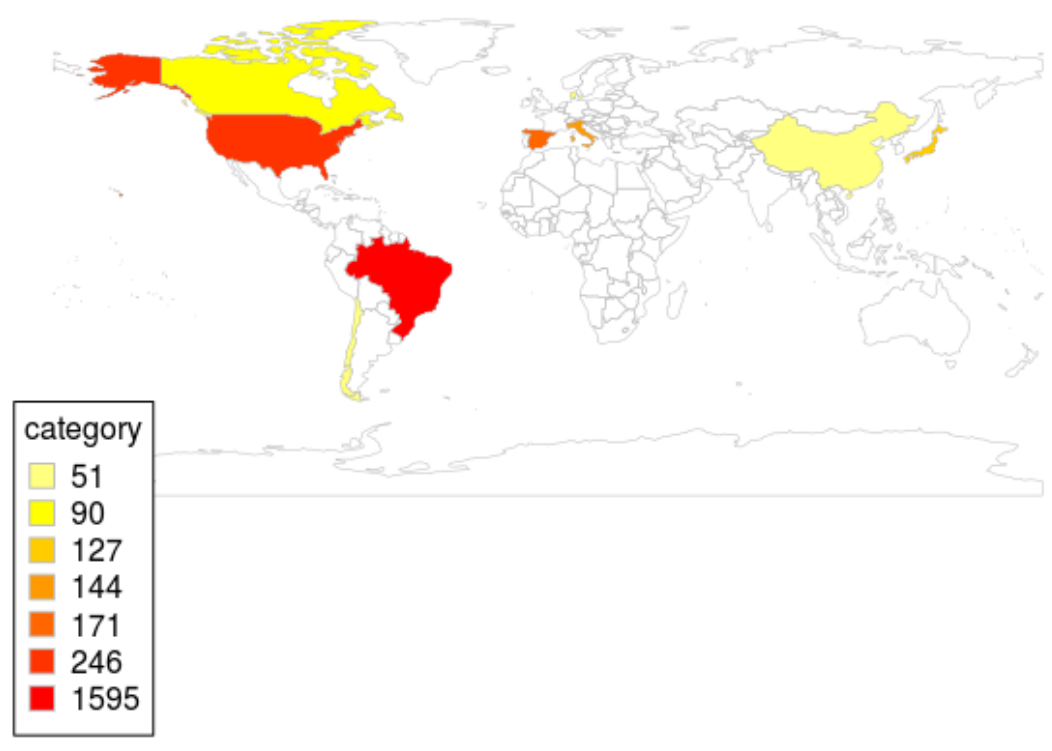

Figura 4: Países com mais citações.

\subsubsection{Palavras relevantes}

Em relação às palavras-chave citadas com maior frequência, podemos destacar a "humanização da assistência", seguida pela "humanização", conforme demonstrado na tabela 02.

Tabela 2: Dez principais palavras chave.

\begin{tabular}{cc}
\hline Palavras & Frequência \\
\hline humanization of assistance & 113 \\
Humanization & 103 \\
Nursing & 40 \\
prenatal care & 32 \\
primary health care & 28 \\
qualitative research & 22 \\
nursing care & 21 \\
institutional support & 20 \\
humanization of care & 18 \\
Ethics & 16 \\
\hline
\end{tabular}

Para uma melhor apresentação dos dados, a figura 05 representa uma nuvem de palavras, onde estão demonstradas as palavras chave que possuem maior número de ocorrências nos artigos selecionados. 


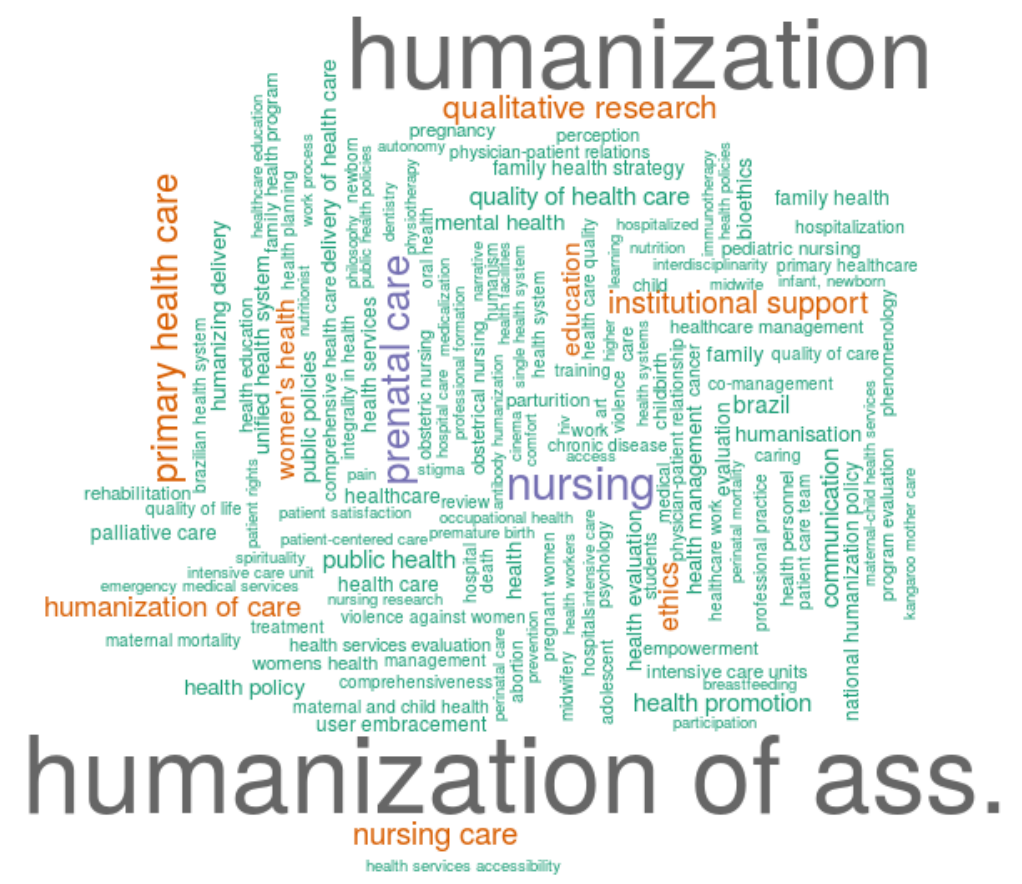

Figura 5: Nuvem de palavras com frequência mínima de 03.

\subsubsection{Autores relevantes}

Quanto aos estudiosos que mais pesquisam sobre o tema, fica evidenciado, através da tabela 03, os autores que mais contribuem com trabalhos nessa área.

Tabela 3: Dez autores mais produtivos.

\begin{tabular}{cc}
\hline Autores & $\mathbf{N}^{\circ}$ de artigos \\
\hline BARROS,MEB & 8 \\
ERDMANN,AL & 8 \\
CAPOLONGO,S & 7 \\
GARBIN,CAS & 6 \\
GOLA,M & 6 \\
MARTINS,CP & 6 \\
ALVES,VH & 5 \\
BACKES,DS & 5 \\
BEHRUZI,R & 5 \\
BUFFOLI,M & 5 \\
\hline
\end{tabular}

\subsubsection{Artigos relevantes}

Através da tabela 4 fica evidente a correlação entre os autores que mais contribuem e o número de citações correspondente. 
Tabela 4: Dez artigos mais citados.

TODRES, L.; GALVIN, K.; DAHLBERG, K. Lifeworld-led Healthcare: Revisiting a Humanising Philosophy that Integrates Emerging Trends. Medicine, Health Care and 103 Philosophy, v. 10, n. 1, p. 53-63, 18 mar. 2007

HUSTON, J. S.; GEORGE, A. J. Engineered antibodies take center stage. Human antibodies, v. 10, n. 3-4, p. 127-42, 2001

CATTANEO, A. et al. Recommendations for the implementation of Kangaroo Mother Care for low birthweight infants. Acta Paediatrica, v. 87, n. 4, p. 440-445, 2 jan. 2007

SERRUYA, S. J.; CECATTI, J. G.; LAGO, T. DI G. DO. O Programa de Humanização no Prénatal e Nascimento do Ministério da Saúde no Brasil: resultados iniciais. Cadernos de Saúde Pública, v. 20, n. 5, p. 1281-1289, out. 2004

CORTÉS-AVIZANDA, A.; CARRETE, M.; DONÁZAR, J. A. Managing supplementary feeding for avian scavengers: Guidelines for optimal design using ecological criteria. Biological Conservation, v. 143, n. 7, p. 1707-1715, jul. 2010

TODRES, L.; GALVIN, K. T.; HOLLOWAY, I. The humanization of healthcare: A value framework for qualitative research. International Journal of Qualitative Studies on Health and Well-being, v. 4, n. 2, p. 68-77, 2009

CARPER, B. et al. A Central Unifying Focus for the Discipline. Advances in Nursing Science, v. 1, n. 1, p. 1-15, 2008

SUZUKI, S. et al. Il2rg gene-targeted severe combined immunodeficiency pigs. Cell Stem Cell, v. 10, n. 6, p. 753-758, 2012.

LEE, L. The Current State of Public Health in China. Annual Review of Public Health, v. 25, n. 1, p. 327-339, 2004.

RAHBARIZADEH, F.; AHMADVAND, D.; SHARIFZADEH, Z. Nanobody; an Old Concept and New Vehicle for Immunotargeting. Immunological Investigations, v. 40, n. 3, p. 299-338, 2011.

\subsubsection{Publicações por área}

O tema é discutido em diversas áreas de estudo, no entanto, a área de Medicina é a que mais se destaca com 58\% das publicações, demonstrando a importância desse tema na formação médica assim como em toda a área da saúde. Na figura abaixo é apresentado um gráfico com a distribuição em cada área. 


\section{Scopus}

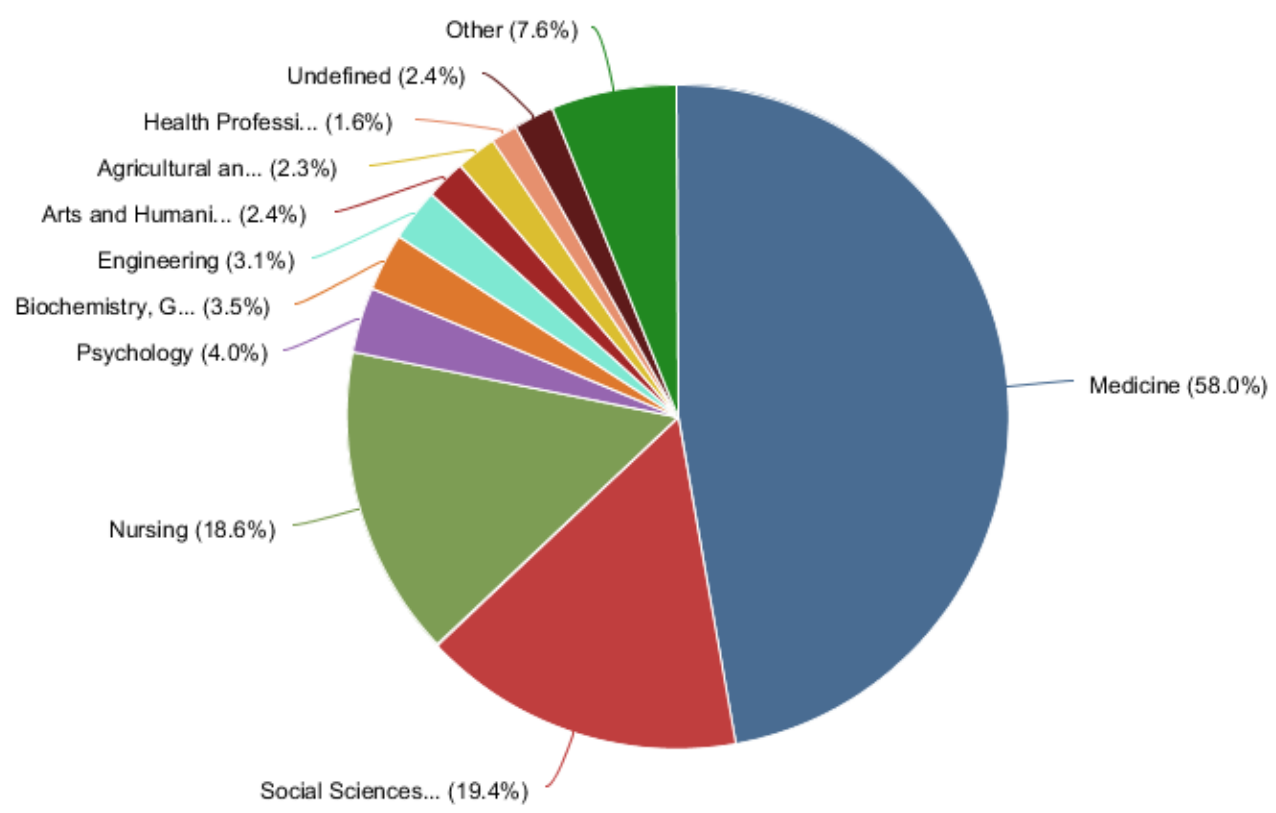

Copyright $@ 2017$ Elsevier B.V. All rights resenved. Scopus@ is a registered trademark of Elsevier B.V.

Figura 6: Publicações em cada área de estudo. Fonte: (Elsevier B. V., 2017).

\subsubsection{Principais Instituições}

As Universidades brasileiras são as principais instituições que publicam sobre humanização e saúde. Ao analisar as instituições é possível observar que o assunto é discutido nas mais variadas regiões do Brasil. A Universidade de São Paulo (USP), com 77 documentos, é a que mais contribui com o tema, seguida da Universidade Federal do Rio de Janeiro (UFRJ), Universidade Federal de Santa Catarina (UFSC) e Fundação Oswaldo Cruz (FIOCRUZ) com 27 publicações cada, conforme a figura 07 que apresenta as 10 principais instituições. 


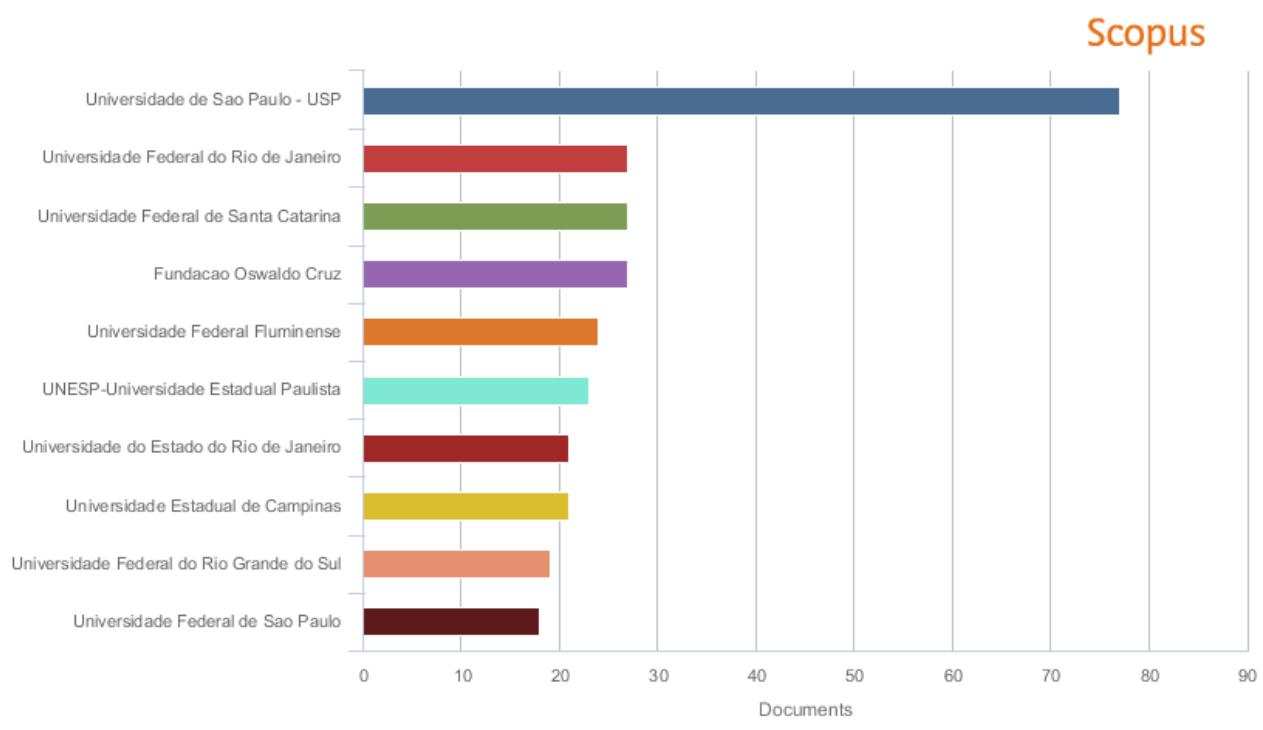

Copyright @ 2017 Elsevier B.V. All rights resened. Scopus B is a registered trademark of Elsevier B.V.

Figura 7: Principais instituições. Fonte: (Elsevier B. V., 2017).

\subsection{Análise de Redes}

\subsubsection{Colaboração entre países}

Na figura 08 é mostrada uma rede de colaboração entre países, onde pode ser observado novamente um destaque para o Brasil, mostrando mais uma vez a importância do país com relação ao tema da pesquisa.

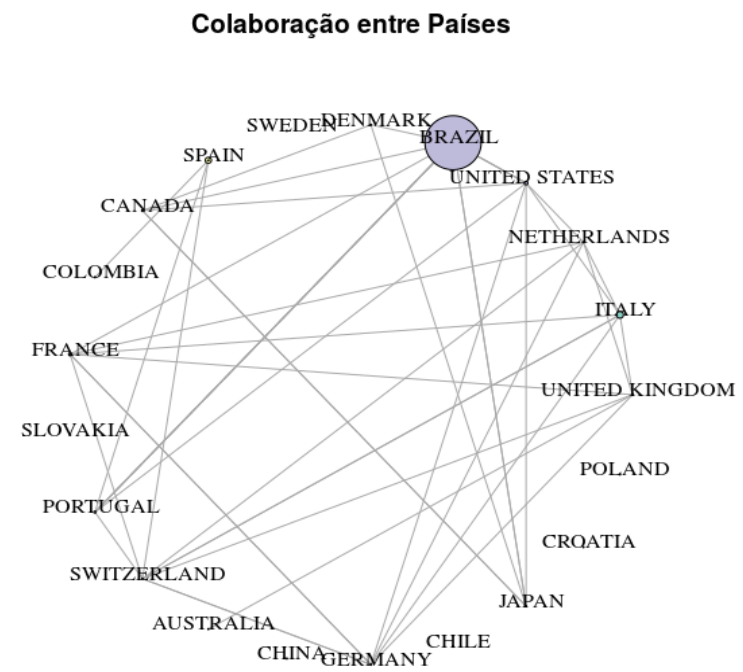

Figura 8: Conexões entre os países que abordam o este assunto. 
ACTA

Biomedica Brasiliensia

ISSN: 2236-0867

\subsubsection{Rede de palavras}

Na figura 09 é mostrada uma rede de co-ocorrência de palavras-chave, com as 20 principais, destacando utilização do tema, humanização na saúde.

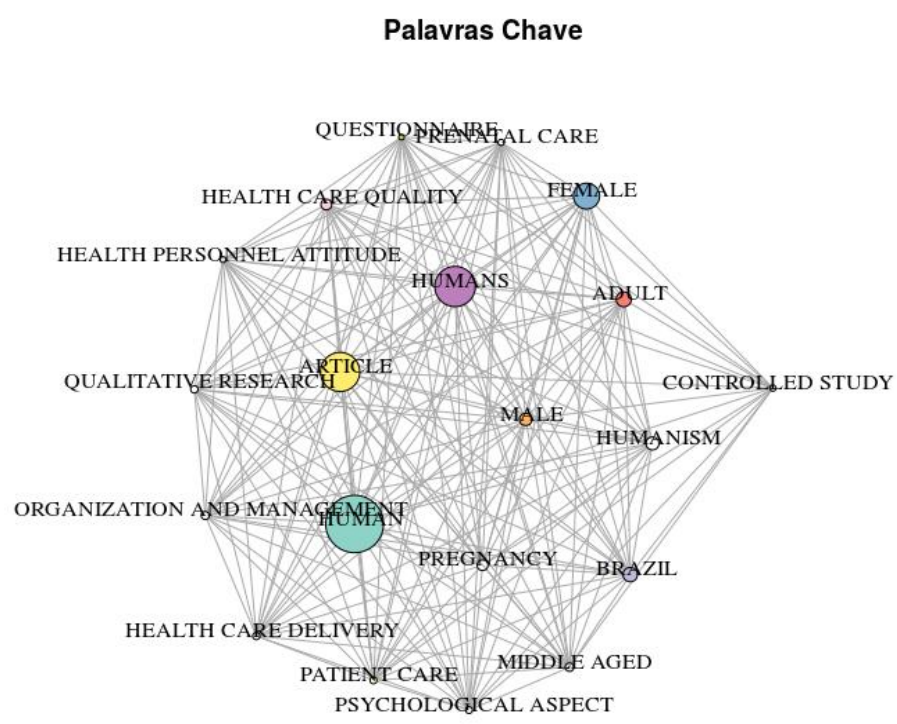

Figura 9: Rede de palavras.

\subsubsection{Rede de cocitação}

Na figura 10 é mostrada uma rede de cocitação, com os 15 principais, destacando utilização termo saúde em português, mais uma confirmando a importância do Brasil com relação ao tema da pesquisa.

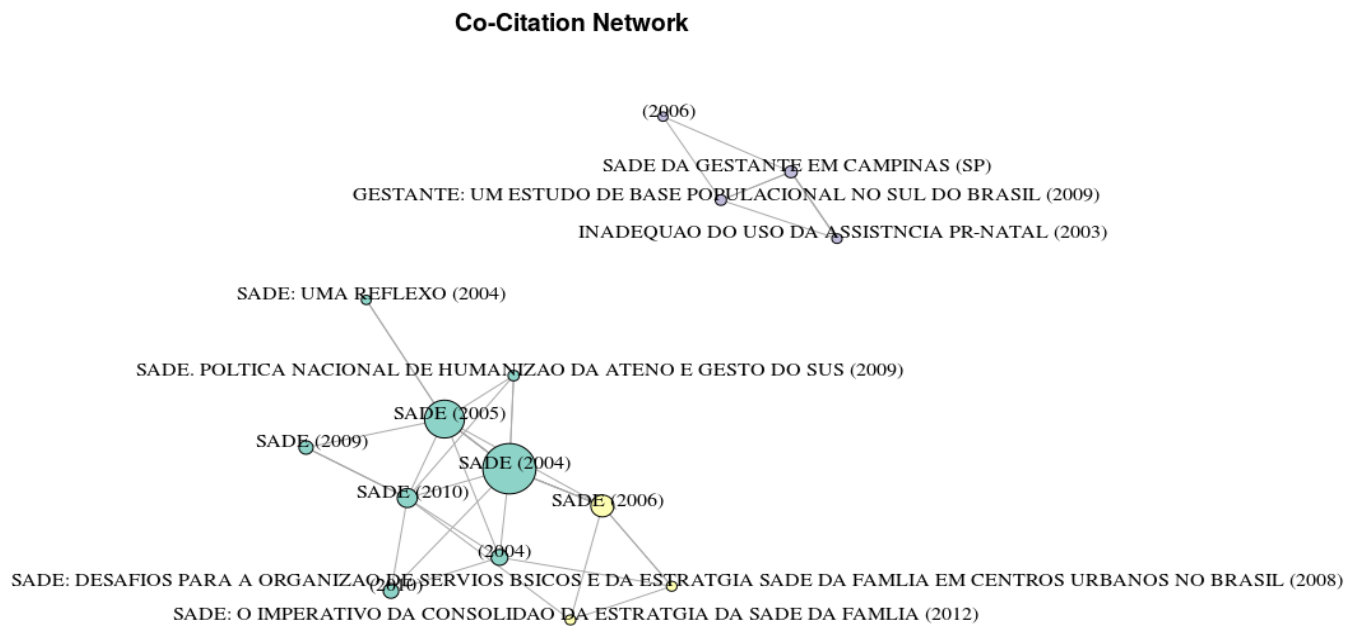

Figura 10: Rede de palavras. 


\section{Conclusão}

A humanização em saúde constitui um processo de transformação do modelo assistencial existente cujo objetivo é demonstrar não somente a importância dos profissionais envolvidos como protagonistas e corresponsáveis por suas práticas, mas também o envolvimento dos cidadãos na saúdedoença. Para isso, é necessário que haja uma formação acadêmica humanizada do profissional médico, a partir do embasamento e conhecimento científico acerca dessa temática tanto dos docentes quanto dos discentes e demais profissionais já graduados.

Desse modo, a bibliometria constitui uma ferramenta de apoio importante para a construção de indicadores e parâmetros para avaliar, quantificar e ordenar a evolução da informação em saúde através da análise em bancos de dados renomados e de produção científica fidedigna.

Através da presente análise, constatou-se que o Brasil é o principal país nas pesquisas sobre o tema com quase $50 \%$ do total de publicações $(48,5 \%)$, fato que pode ser justificado com os constantes investimentos do governo em humanização dos profissionais da saúde, principalmente os médicos (Lorenzoni, 2005). Consequentemente, as principais instituições que publicam sobre o tema são brasileiras, destacando a Universidade São Paulo (USP) que possui quase 9\% do total de publicações de todo o mundo, refletindo também na análise dos periódicos, pois 8 dos 10 principais são do Brasil, evidenciando um vertiginoso interesse a respeito do assunto.

Assim, a pesquisa elucidou a saliência da humanização, principalmente na área da saúde, onde o maior número de publicações foi na área médica. Tal fato contribui para a construção da educação em saúde, principalmente para a formação discente do médico, baseada em uma medicina que contemple as reais necessidades dos pacientes enquanto "seres humanos", dotados de um contexto biopsicossocial, bem como estabelecendo um vínculo empático na relação médico e paciente.

\section{6 referências}

ARIA, M.; CUCCURULLO, C. bibliometrix: An R-tool for comprehensive science mapping analysis. Journal of Informetrics, v. 11, n. 4, p. 959-975, 2017.

BRASIL. HumanizaSUS. Ministério da Saúde, secretaria executiva, núcleo técnico da política nacional de Humanizaçã. Brasília, p. 1-19, 2004.

CARPER, B. et al. A Central Unifying Focus for the Discipline. Advances in Nursing Science, v. 1, n. 1, p. 1-15, 2008.

CATTANEO, A.; DAVANZO, R.; UXA, F.; TAMBURLINI, G. Recommendations for the implementation of Kangaroo Mother Care for low birthweight infants. Acta Paediatrica, v. 87, n. 4, p. 440-445, 2 jan. 2007.

CORTÉS-AVIZANDA, A.; CARRETE, M.; DONÁZAR, J. A. Managing supplementary feeding for avian scavengers: Guidelines for optimal design using ecological criteria. Biological Conservation, v. 143, n. 7, p. 1707-1715, jul. 2010.

ELSEVIER B. V. Scopus. Disponível em: 〈https://www.scopus.com>. Acesso em: 3 fev. 2017.

FALAGAS, M. E.; PITSOUNI, E. I.; MALIETZIS, G. A.; PAPPAS, G. Comparison of PubMed, Scopus, Web of Science, and Google Scholar: strengths and weaknesses. The FASEB Journal, v. 22, 
n. 2, p. 338-342, 2007.

FELLOWS, I. Package "wordcloud"R package version 2.5, 2014. Disponível em: <https://cran.rproject.org/web/packages/wordcloud/index.html>

HUSTON, J. S.; GEORGE, A. J. Engineered antibodies take center stage. Human antibodies, v. 10, n. 3-4, p. 127-42, 2001.

KHABSA, M.; GILES, C. L. The number of scholarly documents on the public web. PLoS ONE, v. 9, n. 5, 2014.

KLINK, S.; REUTHER, P.; WEBER, A.; WALTER, B.; LEY, M. Analysing Social Networks Within Bibliographical Data. In: BRESSAN, S.; KÜNG, J.; WAGNER, R. (Eds.). . Database and Expert Systems Applications: 17th International Conference, DEXA 2006, Krak\{ó\}w, Poland, September 4-8, 2006. Proceedings. Berlin, Heidelberg: Springer Berlin Heidelberg, 2006. p. 234243.

KNUTAS, A.; HAJIKHANI, A.; SALMINEN, J.; IKONEN, J.; PORRAS, J. Cloud-based Bibliometric Analysis Service for Systematic Mapping Studies. Proceedings of the 16th International Conference on Computer Systems and Technologies, p. 184-191, 2015.

LEE, L. The Current State of Public Health in China. Annual Review of Public Health, v. 25, n. 1, p. 327-339, 2004.

LORENZONI, I. MEC investe na humanização dos médicos - MEC. Disponível em: <http://portal.mec.gov.br/ultimas-noticias/212-educacao-superior-1690610854/1778-sp-44076951>. Acesso em: 25 nov. 2017.

MENA-CHALCO, J. P.; JUNIOR, R. M. C. scriptLattes: an open-source knowledge extraction system from the Lattes platform. Journal of the Brazilian Computer Society, v. 15, n. 4, p. 31-39, 2009.

OLIVEIRA, B. R. G. DE; COLLET, N.; VIERA, C. S. A humanização na assistência à saúde. Revista Latino-Americana de Enfermagem, v. 14, n. 2, p. 277-284, 2006.

OTTE, E.; ROUSSEAU, R. Social network analysis: a powerful strategy, also for the information sciences. Journal of Information Science, v. 28, n. 6, p. 441-453, 2002.

PETERSEN, K.; VAKKALANKA, S.; KUZNIARZ, L. Guidelines for conducting systematic mapping studies in software engineering: An update. Information and Software Technology, v. 64, p. 1-18, 2015.

R DEVELOPMENT CORE TEAM. R: A language and environment for statistical computingR Foundation for Statistical ComputingVienna, Austria, 2010. Disponível em: <http://www.rproject.org/>

RAHBARIZADEH, F.; AHMADVAND, D.; SHARIFZADEH, Z. Nanobody; an Old Concept and New Vehicle for Immunotargeting. Immunological Investigations, v. 40, n. 3, p. 299-338, 2011. 
RIOS, I. C. Humanização: a essência da ação técnica e ética nas práticas de saúde. Revista Brasileira de Educação Médica, v. 33, n. 2, p. 253-261, 2009.

SCHRAIBER, L. B. No encontro da técnica com a ética: o exercício de julgar e decidir no cotidiano do trabalho em medicina. Interface - Comunicação, Saúde, Educação, v. 1, n. 1, p. 123-140, 1997.

SERRUYA, S. J.; CECATTI, J. G.; LAGO, T. DI G. DO. O Programa de Humanização no Pré-natal e Nascimento do Ministério da Saúde no Brasil: resultados iniciais. Cadernos de Saúde Pública, v. 20, n. 5, p. 1281-1289, out. 2004.

SOUTH, A. rworldmap: A New R package for Mapping Global Data. The R Journal, v. 3, p. 35-43, 2011.

SUZUKI, S. et al. Il2rg gene-targeted severe combined immunodeficiency pigs. Cell Stem Cell, v. 10, n. 6, p. 753-758, 2012.

TODRES, L.; GALVIN, K. T.; HOLLOWAY, I. The humanization of healthcare: A value framework for qualitative research. International Journal of Qualitative Studies on Health and Well-being, v. 4, n. 2, p. 68-77, 2009.

TODRES, L.; GALVIN, K.; DAHLBERG, K. Lifeworld-led Healthcare: Revisiting a Humanising Philosophy that Integrates Emerging Trends. Medicine, Health Care and Philosophy, v. 10, n. 1, p. 53-63, 18 mar. 2007. 